\title{
GMR
}

\section{Effect of transvaginal ultrasound on human chorionic villus cell apoptosis during pregnancy}

\author{
X.L. Qu ${ }^{1,2}$, H.T. Wang ${ }^{1,2}$, J.L. Zou' ${ }^{2}$, L. Cheng ${ }^{1}$, F. Wang ${ }^{2}$, L.L. $\mathrm{Ma}^{2}$ and J. $\mathrm{Li}^{1}$ \\ 'Department of Ultrasonography, Qilu Hospital of Shandong University, Jinan, \\ Shandong, China \\ 2Department of Ultrasonography, Shandong Weihai Municipal Hospital, Weihai, \\ Shandong, China \\ Corresponding author: J. Li \\ E-mail: mondaywillbehai@163.com
}

Genet. Mol. Res. 14 (4): 18771-18777 (2015)

Received August 12, 2015

Accepted October 16, 2015

Published December 28, 2015

DOI http://dx.doi.org/10.4238/2015.December.28.26

ABSTRACT. With the advancement of ultrasonic technology in recent years, sonography has become a common medical diagnostic tool, as it has elevated output sonic intensity and elongated exposure time. This study investigates the effect of ultrasound on human chorionic villus cell apoptosis during early pregnancy. Transvaginal ultrasound was performed for a total of 60 women who had undergone induced abortion at our hospital. They were randomly divided into the control, short ultrasound (10 $\mathrm{min}$ ), and long ultrasound (20 min) groups ( $N=20$ each). Twenty-four hours after ultrasonic exposure, chorionic villus tissues were extracted during induced abortion, and were tested for cell apoptosis using flow cytometry. Bax and B cell lymphoma-2 (Bcl-2) protein levels were also quantified by immunohistochemistry. We found that the long ultrasound group had significantly higher cell apoptosis rates compared to the short ultrasound group, which in turn had higher rates compared to the control group ( $\mathrm{P}<$ 0.05 in both cases). Bax protein levels were elevated in both the long and 
short ultrasound groups $(\mathrm{P}<0.05)$. Bcl-2 proteins in two ultrasound groups, however, were downregulated as compared to those in the control group $(P$ $<0.05)$. It is therefore possible that transvaginal sonography can potentiate the apoptosis of human chorionic villus cells by increasing the $\mathrm{Bax} / \mathrm{Bcl}-2$ protein ratio.

Key words: Transvaginal ultrasound; Human chorionic villus cells; Cell apoptosis; Bax/Bcl-2

\section{INTRODUCTION}

Cell apoptosis, as one of the programmed cell death mechanisms, is of critical importance for body homeostasis under normal physiological conditions (Longtine et al., 2012). The disruption of normal apoptosis, however, may lead to severe consequences such as premature delivery, which is believed to be related to abnormal apoptosis of placental cells (Bosco et al., 2015). Transvaginal ultrasound has been widely used in gynecologic practice (Ikpeme et al., 2014) due to its inherent advantages, including proximity to the target tissue, higher frequency of the probe, and higher-resolution images (Kubešová al., 2013). Morphological alterations in chorionic villus cells under ultrasound have been studied; significant changes were observed in microscopic structure after 5-min high frequency exposure under transvaginal sonography but not abdominal sonography until $20 \mathrm{~min}$ later. These phenomena raised the issue of the effect of ultrasound on embryonic tissue morphology. This study therefore aimed to investigate if transvaginal ultrasound can regulate apoptosis of human chorionic villus cells, via clinical study of early-pregnant patients undergoing induced abortion.

\section{MATERIAL AND METHODS}

\section{General information of patients}

A total of sixty pregnant women (age: 21-35 years; average age: 28.4 years old) who underwent induced abortion surgery at Shandong Weihai Municipal Hospital between January 2014 and January 2015 were recruited in this study. The average pregnancy time of all patients was 53.8 days. All patients had normal embryo buds and primitive heart beats. The average diameter of gestational sacs was $2.2 \mathrm{~cm}$. None of the participants had any history of miscarriage, exposure to toxicity, radiation or drug abuse. This study has been pre-approved by the ethical committee of our hospital, and written consent was obtained from all subjects involved in the study.

\section{Grouping and sonography}

Patients were randomly divided into three groups: control, short ultrasound, and long ultrasound groups ( $\mathrm{N}=20$ per group). Control patients were not exposed to ultrasound. The patients in the short and long ultrasound groups underwent transvaginal sonography with a 5.0 $\mathrm{MHz}$ high frequency probe (VolusonS6, GE, USA). Short ultrasound group patients were exposed for $10 \mathrm{~min}$, while the long ultrasound group received $30 \mathrm{~min}$ ultrasound treatment. After $24 \mathrm{~h}$, induced abortion surgery was performed for all patients, during which period chorionic villus tissues were extracted and rinsed in saline. Half of the tissue samples were digested and analyzed by flow 
cytometry (Jinghong, China). The other half of tissue samples was fixed in $10 \%$ neutral buffered formalin (NBF) for further staining.

\section{Flow cytometry}

Human chorionic villus tissues were first rinsed in PBS and cut into small pieces, which were digested by $0.25 \%$ pepsin. Cells were then re-suspended in PBS, centrifuged at $1000 \mathrm{~g}$ for $15 \mathrm{~min}$, and washed twice. Cells were fixed in $70 \%$ ethanol at $4^{\circ} \mathrm{C}$ overnight. Before loading, cells were prepared suspended in PBS with $50 \mu \mathrm{g} / \mathrm{mL}$ RNaseA. After $30-\mathrm{min}$ incubation at $37^{\circ} \mathrm{C}$, cells were stained with propidium iodide (PI) for $30 \mathrm{~min}$. Samples were then loaded onto the flow analyzer (Jinghong, China) to analyze the cell cycle.

\section{Immunohistochemical (IHC) staining and analysis}

Human chorionic villus tissues were embedded in paraffin after NBF fixation. Tissues were then sectioned into 5- $\mu \mathrm{m}$-thick slices using a microtome (Leica, Germany), and were mounted onto glass slides. After de-waxing and heated antigen retrieval, endogenous peroxidase activity was quenched by $3 \%$ hydrogen peroxide. Non-specific binding sites were blocked via incubation with normal goat serum (NGS) at room temperature. Tissue sections were incubated with rabbit antihuman Bax or B cell lymphoma-2 (Bcl-2) polyclonal antibody (1:100, Cell Signaling, USA) for $1 \mathrm{~h}$ at room temperature. Goat anti-rabbit IgG antibody conjugated with horseradish peroxidase (1:100, Cell Signaling) was then added for $10 \mathrm{~min}$. Streptavidin-peroxidase was finally added for $10 \mathrm{~min}$. Hematoxylin was used to counterstain the tissue. Images were captured on an inverted light-field microscope (Olympus, Japan).

Parallel negative controls were stained using PBS instead of primary antibody. Positive controls were obtained by staining known Bax or Bcl-2 positive tissue samples. A positive signal was identified when brown or yellow-brown granules were found in the membrane or cytoplasm of the cell, but not in the nucleus. The results were graded based on the percentage of positive cells in one of the five randomly selected field of views. In detail, negative (-) was defined as when the positive cell percentage was $<10 \%$; weak positive $(+)$ staining was defined as when positive cells accounted for $11-25 \%$ of total cells; positive (++) was defined as when $26-50 \%$ of total cells showed positive signals; strong positive $(+++)$ staining was defined as when more than half of the total cells displayed a positive signal. The latter three of those categories $(+,++$ and +++$)$ were included as positive staining.

\section{Data analysis}

The SPSS 17.0 software package was used to analyze all collected data. Data are presented as mean \pm standard deviation (SD), and were analyzed by the chi-square test. Differences between groups were determined by analysis of variance (ANOVA). Statistical significance was reached when $\mathrm{P}<0.05$.

\section{RESULTS}

\section{Apoptosis of human chorionic villus cells}

We employed flow cytometry to evaluate apoptosis of human chorionic villus cells in both 
control and experimental groups. The results (Table 1, Figure 1) showed significantly greater apoptosis in the long ultrasound group as compared to the short ultrasound group $(P<0.05)$. In addition, cell apoptosis in the short ultrasound group was also significantly higher as compared to that in the control group $(P<0.05)$. Further comparison of early/late stage apoptosis also showed significantly potentiated cell apoptosis in both early and late stage when 30-min ultrasound was applied (Table 2).

Table 1. Apoptotic rates of human chorionic villus cells.

\begin{tabular}{lcccc}
\hline Group & \multicolumn{2}{c}{ Relative cell number } & Apoptotic rate (\%) \\
\cline { 2 - 5 } & Normal & Apoptotic & Sum & 16.79 \\
\hline Control & 9,421 & 1,901 & 11,322 & $36.60^{*}$ \\
Short ultrasound & 11,246 & 6,492 & 17,738 & $76.89^{\star *}$ \\
Long ultrasound & 5,104 & 16,984 & 22,088 & 7 \\
\hline
\end{tabular}

${ }^{*} \mathrm{P}<0.05$ compared to the control group; ${ }^{\mathrm{P}}<0.05$ compared to the short ultrasound group.
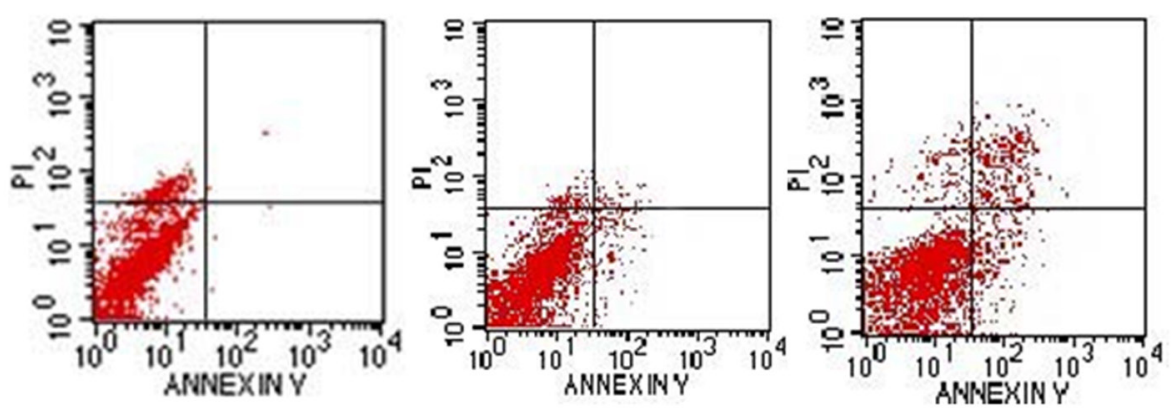

Figure 1. Flow cytometry showing cell apoptosis.

Table 2. Early- and late-stage apoptosis.

\begin{tabular}{lll}
\hline Group & \multicolumn{2}{c}{ Human chorionic villus cells } \\
\cline { 2 - 3 } & Early stage & Late stage \\
\hline Control & $0.19 \pm 0.04$ & $0.13 \pm 0.02$ \\
Short ultrasound & $1.67 \pm 0.59^{*}$ & $3.22 \pm 0.24^{*}$ \\
Long ultrasound & $8.92 \pm 0.94^{\text {*\#}}$ & $6.97 \pm 0.71^{\star *}$ \\
\hline
\end{tabular}

${ }^{*} \mathrm{P}<0.05$ compared to the control group; ${ }^{*} \mathrm{P}<0.05$ compared to the short ultrasound group.

\section{Bax and $\mathrm{Bcl}-2$ protein expression}

We further used IHC staining to detect protein expression of Bax and $\mathrm{Bcl}-2$ in chorionic villus tissues. Microscopic images (Figures 2 and 3 ) showed membrane and cytosolic expression of those two proteins as brown or yellow granules. In the control group, Bax was mainly expressed in the membrane and cytosol of syncytiotrophoblast cells. In the cells exposed to ultrasound, however, it was distributed in both syncytiotrophoblast cells and cytotrophoblastic cells (Figure 2). Its expression level, as suggested by the staining intensity, increased with elongated exposure time to ultrasound. $\mathrm{Bcl}-2$ protein was expressed in the membrane and cytosol of cytotrophoblastic cells in both the control and the ultrasound groups, the latter of which, however, showed reduction in expression, which was time-dependent (Figure 3). 
Further comparisons between the two ultrasound groups (Table 3) showed elevated Bax expression in the long ultrasound group as compared to that in the short ultrasound group (70 vs $50 \%, \mathrm{P}<0.05)$. Bcl-2 expression was lower in both ultrasound groups as compared to the control, but did not show significant difference between the two experimental groups $(P>0.05)$.

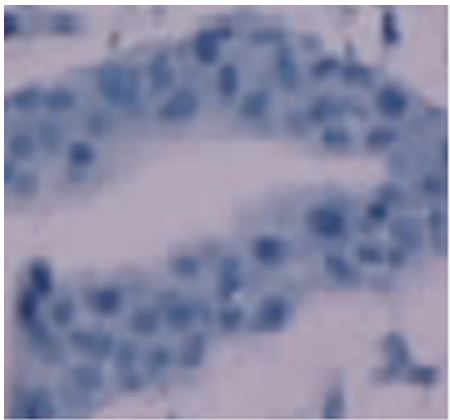

Control

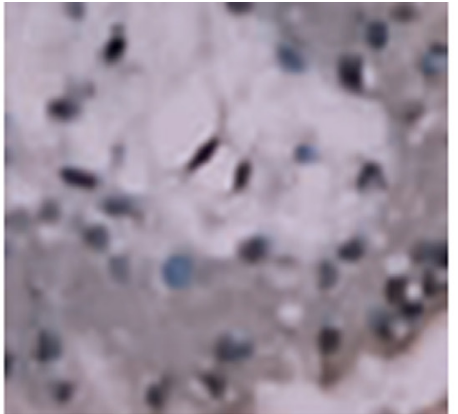

\section{Short ultrasound}

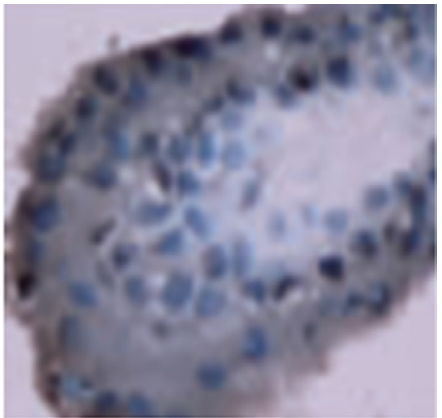

Long ultrasound

Figure 2. Bax protein expression in chorionic villus tissues. Left: control group with weak positive expression (+); middle: short ultrasound group with positive expression $(++)$; right: long ultrasound group with strong positive expression (+++). Magnification: 400X.



Control

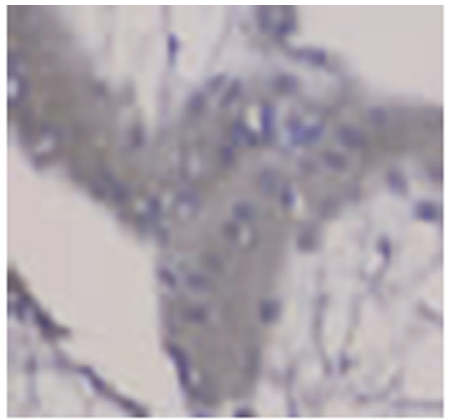

Short ultrasound

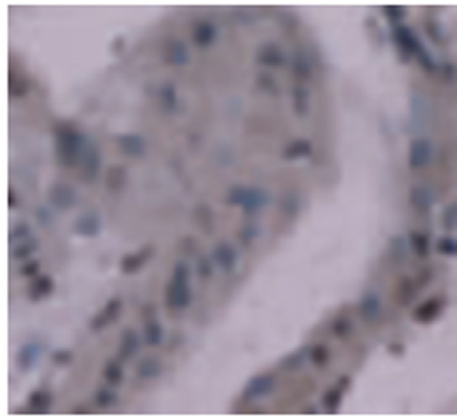

Long ultrasound

Figure 3. Bcl-2 protein expression in chorionic villus tissues. Left: control group with weak positive expression $(+)$; middle: short ultrasound group with positive expression $(++)$; right: long ultrasound group with strong positive expression (+++). Magnification: 400X.

Table 3. Bax and $\mathrm{Bcl}-2$ protein expression in chorionic villus tissues.

\begin{tabular}{|c|c|c|c|c|c|c|c|c|c|}
\hline \multirow[t]{2}{*}{ Group } & \multirow[t]{2}{*}{$N$} & \multicolumn{4}{|c|}{ Bax } & \multicolumn{4}{|c|}{ Bcl-2 } \\
\hline & & - & ++ & +++ & Positive \% & - & ++ & +++ & Positive \% \\
\hline Control & 20 & 17 & 3 & 0 & 15 & 14 & 5 & 1 & 30 \\
\hline Short Ultrasound & 20 & 10 & 7 & 3 & $50^{*}$ & 16 & 3 & 1 & 20 \\
\hline Long Ultrasound & 20 & 6 & 9 & 5 & $70^{\text {*\# }}$ & 17 & 3 & 0 & 15 \\
\hline
\end{tabular}

${ }^{*} \mathrm{P}<0.05$ compared to the control group; ${ }^{\mathrm{P}}<0.05$ compared to the short ultrasound group. - indicates negative. ++ indicates positive. +++ indicates strong positive. 


\section{DISCUSSION}

Apoptosis, a form of programmed cell death, can maintain body homeostasis via elimination of mutated or aging cells (Duaso et al., 2011). Past studies have revealed simultaneous cell proliferation and apoptosis during embryonic and placenta development (Stanek, 2010). Apoptosis of trophoblasts was also observed in mice with premature delivery but not in those with term delivery (Bertucci et al., 2011), suggesting a relationship between cell apoptosis and premature delivery.

Ultrasound has now been widely used in clinics due to its multiple biological functions, including serving mechanic, thermodynamic and cavitation effects (Calzarossa et al., 2013). However, exposure of embryonic mice to color Doppler ultrasound for $30 \mathrm{~min}$ has been reported to induce death in myocardial cells (Jia et al., 2005). Transvaginal ultrasound, when compared with the fetal fibronectin screening test, has inherent advantages, including higher frequency, proximity to the target organ, and higher resolution (Tanvir et al., 2014). Recently, molecular effects of transvaginal ultrasound including biochemical functions, gene mutation, cell apoptosis, and morphological alternations have been studied. For example, structural alterations, functional alternations, or even gene mutations of embryos were observed after 10-min high frequency transvaginal ultrasound exposure (Ochiai et al., 2012; Son et al., 2014; Sayrac et al., 2015).

In this study, we found a significantly elevated apoptotic rate in human chorionic villus tissues following long ultrasound exposure, when compared to short ultrasound exposure and the control (76.89 vs 36.60 vs $16.79 \%$ ). The results suggest that ultrasound exposure may have an effect on cell apoptosis. This is consistent with previous studies where morphological alternations in chorionic cells were observed after 5-min high frequency transvaginal ultrasound or 20-min abdominal ultrasound exposure (Liu et al., 2013). When cells were exposed to 10-min transvaginal high frequency ultrasound, apoptosis increased as well (Ratto et al., 2011), which is consistent with our study results.

Both Bax and Bcl-2 proteins participate in the process of cell death, and are known as key apoptotic proteins (Murphy et al., 2000; Hajiahmadi et al., 2015). Bcl-2 overexpression can inhibit release of cytochrome $\mathrm{c}$, while Bax protein is a positive regulator of cytochrome $\mathrm{c}$ and thus of apoptosis (Reed, 2006; Shirali et al., 2013). This study examined Bax and Bcl-2 protein expression by IHC and found membrane and cytosolic expression of both proteins. In brief, Bax protein was expressed in the syncytiotrophoblasts but Bcl-2 proteins were expressed in both syncytiotrophoblasts and cytotrophoblastic cells. We also found increased Bax, but decreased Bcl2 protein levels with elongated ultrasound exposure, suggesting that disruption of $\mathrm{Bax} / \mathrm{Bcl}-2$ ratio may be crucial for initiation of apoptosis (Abarikwu and Farombi, 2015).

In summary, transvaginal ultrasound increases apoptosis in human chorionic villus tissues, possibly via elevating Bax and suppressing Bcl-2 protein expression. However, the threshold protein expression required to induce excessive apoptosis in chorionic villus tissues requires further research.

\section{Conflicts of interest}

The authors declare no conflicts of interest.

\section{ACKNOWLEDGMENTS}

We thank the anonymous reviewers for reviewing this manuscript. 


\section{REFERENCES}

Abarikwu SO and Farombi EO (2015). Atrazine induces apoptosis of SH-SY5Y human neuroblastoma cells via the regulation of Bax/Bcl-2 ratio and caspase-3-dependent pathway. Pestic. Biochem. Physiol. 118: 90-98.

Bertucci E, Pati M, Cani C, Volpe A, et al. (2011). The transvaginal probe as a uterine manipulator: a new technique to simplify transabdominal chorionic villus sampling in cases with difficult access to the trophoblast. Prenatal Diagn. 31: 897-900.

Bosco C, Diaz E, Gutiérrez R, Gonzaléz J, et al. (2015). Placental hypoxia developed during preeclampsia induces telocytes apoptosis in chorionic villi affecting the maternal-fetus metabolic exchange. Curr. Stem Cell Res. Ther. [Epub ahead of print].

Calzarossa C, Bossolasco P, Besana A, Manca MP, et al. (2013). Neurorescue effects and stem properties of chorionic villi and amniotic progenitor cells. Neuroscience 234: 158-172.

Duaso J, Rojo G, Jaña F, Galanti N, et al. (2011). Trypanosoma cruzi induces apoptosis in ex vivo infected human chorionic villi. Placenta 32: 356-61.

Hajiahmadi S, Panjehpour M, Aghaei M and Shabani M (2015). Activation of A2b adenosine receptor regulates ovarian cancer cell growth: involvement of Bax/Bcl-2 and caspase-3. Biochem. Cell Biol. 93: 321-329.

Ikpeme AA, Udo AE and Ani NE (2014). Transvaginal ultrasound assessment of women presenting with infertility and menstrual irregularity in Calabar, Nigeria. Niger. Postgrad. Med. J. 21: 262-265.

Jia H, Duan Y, Cao T, Zhao B, et al. (2005). Immediate and long-term effects of color Doppler ultrasound on myocardial cell apoptosis of fetal rats. Echocardiography 22: 415-420.

Kubešová B, Líbalová P, Simonová V, Bucharová J, et al. (2013). Retrospective analysis of effectiveness of transvaginal ultrasound in the detection of ectopic pregnancy. Ceska Gynekol. 78: 338-341.

Liu H, Hou F, Liang H, Liu G, et al. (2013). Effects of diagnostic ultrasound on HSP70 expression in chorionic villi in rats during early pregnancy and the role of HSP70 in apoptosis in chorionic villi. Int. J. Mol. Med. 32: 1085-1092.

Longtine MS, Chen B, Odibo AO, Zhong Y, et al. (2012). Caspase-mediated apoptosis of trophoblasts in term human placental villi is restricted to cytotrophoblasts and absent from the multinucleated syncytiotrophoblast. Reproduction 143: 107-121.

Murphy KM, Streips UN and Lock RB (2000). Bcl-2 inhibits a Fas-induced conformational change in the Bax N terminus and Bax mitochondrial translocation. J. Biol. Chem. 275: 17225-17228.

Ochiai D, Omori S, Ikeda T, Yakubo K, et al. (2012). Prenatal diagnosis of dilated cavum vergae with three-dimensional transvaginal ultrasound. Arch. Gynecol. Obstet. 286: 1073-1074.

Ratto MH, Peralta OA, Mogollon G, Strobel P, et al. (2011). Transvaginal ultrasound-guided cumulus oocyte complexes aspiration and in vitro embryo production in suckled beef and lactating dairy cattle on pasture-based management conditions. Anim. Reprod. Sci. 129: 1-6.

Reed JC (2006). Proapoptotic multidomain Bcl-2/Bax-family proteins: mechanisms, physiological roles, and therapeutic opportunities. Cell Death Differ. 13: 1378-1386.

Sayrac N, Bektas F, Soyuncu S and Sayrac V (2015). The impact of goal-directed transvaginal ultrasonography on clinical decision-making for emergency physicians. Am. J. Emerg. Med. 33: 895-898.

Shirali S, Aghaei M, Shabani M, Fathi M, et al. (2013). Adenosine induces cell cycle arrest and apoptosis via cyclinD1/Cdk4 and Bcl-2/Bax pathways in human ovarian cancer cell line OVCAR-3. Tumour Biol. 34: 1085-1095.

Son JB, Jeong JE, Joo JK, Na YJ, et al. (2014). Measurement of endometrial and uterine vascularity by transvaginal ultrasonography in predicting pregnancy outcome during frozen-thawed embryo transfer cycles. J. Obstet. Gynaecol. Res. 40: 1661-1667.

Stanek J (2010). Membrane microscopic chorionic pseudocysts are associated with increased amount of placental extravillous trophoblasts. Pathology 42: 125-130.

Tanvir, Ghose S, Samal S, Armugam S, et al. (2014). Measurement of cervical biometry using transvaginal ultrasonography in predicting preterm labor. J. Nat. Sci. Biol. Med. 5: 369-372. 